Review

\title{
Engineering Hepadnaviruses as Reporter-Expressing Vectors: Recent Progress and Future Perspectives
}

\author{
Weiya Bai ${ }^{\dagger}$, Xiaoxian Cui ${ }^{\dagger}$, Youhua Xie * and Jing Liu * \\ Key Laboratory of Medical Molecular Virology (MOH \& MOE) and Institutes of Biomedical Sciences, \\ School of Basic Medical Sciences, Shanghai Medical College, Fudan University, Shanghai 200032, China; \\ bwy.1989@163.com (W.B.); cuixiaoxian9@hotmail.com (X.C.) \\ * Correspondence: yhxie@fudan.edu.cn (Y.X.); liujing212@fudan.edu.cn (J.L.); Tel.: +86-21-54237972 \\ + These authors contributed equally to this work.
}

Academic Editor: Luis Martinez-Sobrido

Received: 29 February 2016; Accepted: 29 April 2016; Published: 10 May 2016

\begin{abstract}
The Hepadnaviridae family of small, enveloped DNA viruses are characterized by a strict host range and hepatocyte tropism. The prototype hepatitis B virus (HBV) is a major human pathogen and constitutes a public health problem, especially in high-incidence areas. Reporter-expressing recombinant viruses are powerful tools in both studies of basic virology and development of antiviral therapeutics. In addition, the highly restricted tropism of HBV for human hepatocytes makes it an ideal tool for hepatocyte-targeting in vivo applications such as liver-specific gene delivery. However, compact genome organization and complex replication mechanisms of hepadnaviruses have made it difficult to engineer replication-competent recombinant viruses that express biologically-relevant cargo genes. This review analyzes difficulties associated with recombinant hepadnavirus vector development, summarizes and compares the progress made in this field both historically and recently, and discusses future perspectives regarding both vector design and application.
\end{abstract}

Keywords: recombinant virus; viral vector; gene delivery; HBV; DHBV

\section{Introduction}

Hepadnaviridae is a family of small, enveloped DNA viruses with notable hepatic tropism, especially in mammals, and transmission is achieved predominantly through parenteral routes [1,2]. The viral genome consists of partially double-stranded, relaxed circular DNA (rcDNA) that is produced through a process involving a reverse transcription step similar to retroviruses [2,3]. These features led to the classification of hepadnaviruses under group VII (dsDNA(RT) or pararetrovirus) in the Baltimore system, along with certain similar DNA viruses infecting plants.

Hepadnaviruses usually have highly-restricted host ranges and have traditionally been classified into two genera based on host specificity $[4,5]$. Orthohepadnaviruses infect mammals, with members including the prototype hepatitis B virus (HBV) of humans, woolly monkey hepatitis B virus (WMHBV), woodchuck hepatitis virus (WHV), and ground squirrel hepatitis virus (GSHV), etc. Avihepadnaviruses infect various domesticated and wild birds, with members including the prototype duck hepatitis $B$ virus (DHBV), as well as heron hepatitis $B$ virus (HHBV), etc. In recent years, the advent and advances of next-generation sequencing and other metagenomics technologies have enabled the discovery of new HBV-like viruses that infect hosts previously not known to be affected by hepadnaviruses, such as bats [6] and fish [7]. In addition, analyses of whole genome sequencing data have also led to the discovery of endogenous hepadnaviral sequences in genomes of avian [8-10] and reptilian [11] species, suggesting a family history spanning millions of years. In light of these recent discoveries, hepadnaviruses, including extant and now extinct ones, are obviously far more diverse than previously understood and the taxonomy may well be expanded and modified in the future. 
Among extant hepadnaviruses, orthohepadnaviruses productively infect only hepatocytes of the liver, whereas DHBV has been shown to additionally infect certain other cell types of the liver and non-liver organs [3]. Hepato-tropism has been considered the result of tissue-specific distribution of both receptor(s) required for viral entry and transcription factors required for viral expression [12,13]. Accordingly, liver pathologies including hepatitis are major manifestations of symptomatic hepadnaviral infections in both human and animals [1,3]. However, as hepadnavirus infection is neither cytopathic nor cytolytic, hepatitis is generally considered a consequence of the activated host immune response against infected hepatocytes.

$\mathrm{HBV}$ is a major human pathogen and constitutes a severe public health problem in high-incidence areas [5,14]. HBV infection of adults is usually asymptomatic or manifests as self-resolving acute hepatitis, while a small percentage of patients fail to clear the virus and become infected for life. Vertical transmission of HBV from infected mothers to neonates typically results in asymptomatic chronic infection accompanied by immunotolerance towards HBV, which would be broken in later life leading to active hepatitis. Chronic HBV infection is associated with higher risks of cirrhosis and hepatocellular carcinoma (HCC) [1]. Although extensive adoption of preventive HBV vaccine has drastically reduced incidence of new infections, the World Health Organization estimated that HBV chronically infects $\sim 240$ million people worldwide and causes about 600,000 related deaths annually [14].

Duck/DHBV and woodchuck/WHV have been used as model systems of HBV infections for decades, and have helped significantly in understanding hepadnavirus virology and developing anti-HBV therapeutics [15]. However, chronic DHBV infection is not associated with liver cirrhosis or HCC in ducks, while WHV-related HCC is mechanistically much more homogenous than HBV-associated human HCC [3], underlining the fact that HBV and human or humanized animal systems are required for studying various important aspects of HBV pathogenesis.

Reverse genetic systems were established for HBV as well as DHBV decades ago and have become standard tools in studies of viral functions as well as virus-host interactions. In contrast, owing to certain characteristics in genome organization and life cycle (see next section), development of reporter-expressing virus systems based on hepadnaviruses has met with far less successes than many other virus families. Nevertheless, recombinant hepadnavirus vector systems could serve as powerful tools for both studying fundamental questions in hepadnavirus virology and evaluating clinical interventions for chronic HBV infection, as have been demonstrated by other recombinant virus systems. In addition, the highly restricted host range and hepato-tropism of HBV makes it a uniquely ideal tool for hepatocyte-targeting applications, such as liver-specific therapeutic gene delivery. This review attempts to summarize difficulties associated with recombinant hepadnavirus vector development and progress made historically and recently, and discuss future perspectives in this field regarding both vector design and application.

\section{Genome Organization and Life Cycle of Hepadnaviruses}

This section will briefly describe aspects of hepadnavirus virology that most pertains to recombinant virus development. For a more detailed discussion of current understandings in this field, readers are referred to comprehensive reviews published recently $[3,12,16]$.

All extant hepadnaviruses have a genome length of $\sim 3.0-3.4 \mathrm{~kb}$ and nearly identical, highly-compact genome organization (Figure 1). The orthohepadnavirus genome contains four overlapping ORFs that encompass the entire genome: preC/C ORF encodes the nucleocapsid protein $\mathrm{C}$ (core, $\mathrm{HBcAg}$ ) and an N-terminally extended secreted form called e antigen (HBeAg) using two distinct start codons; P ORF encodes the viral polymerase; preS1/preS2/S ORF encodes three co-terminal forms of viral envelope protein named small (S), middle (M), and large (L) surface antigen (HBsAg) that are translated from three distinct start codons; X ORF encodes the $\mathrm{X}$ protein (HBx) that plays multiple functions in the viral life cycle and virus-host interactions. Compared to orthohepadnaviruses, avihepadnaviruses harbor a preS/S ORF, instead of preS1/preS2/S, that only encodes two forms of co-terminal envelope proteins, and avihepadnaviral $\mathrm{P}$ and preC/C ORFs overlap each other, lacking a 
conventional X ORF in between (Figure 1A). In addition to overlapping ORFs, hepadnaviral genomes also contain multiple cis-acting elements essential for various steps of the viral life cycle: promoters (Cp, Sp1, Sp2, and Xp) and enhancers (EnI and EnII) for transcription, epsilon (encapsidation) signal for initiation of reverse transcription and capsid packaging, direct repeats 1 and 2 (DR1 and DR2) for polymerase translocation during genome replication, etc.

A

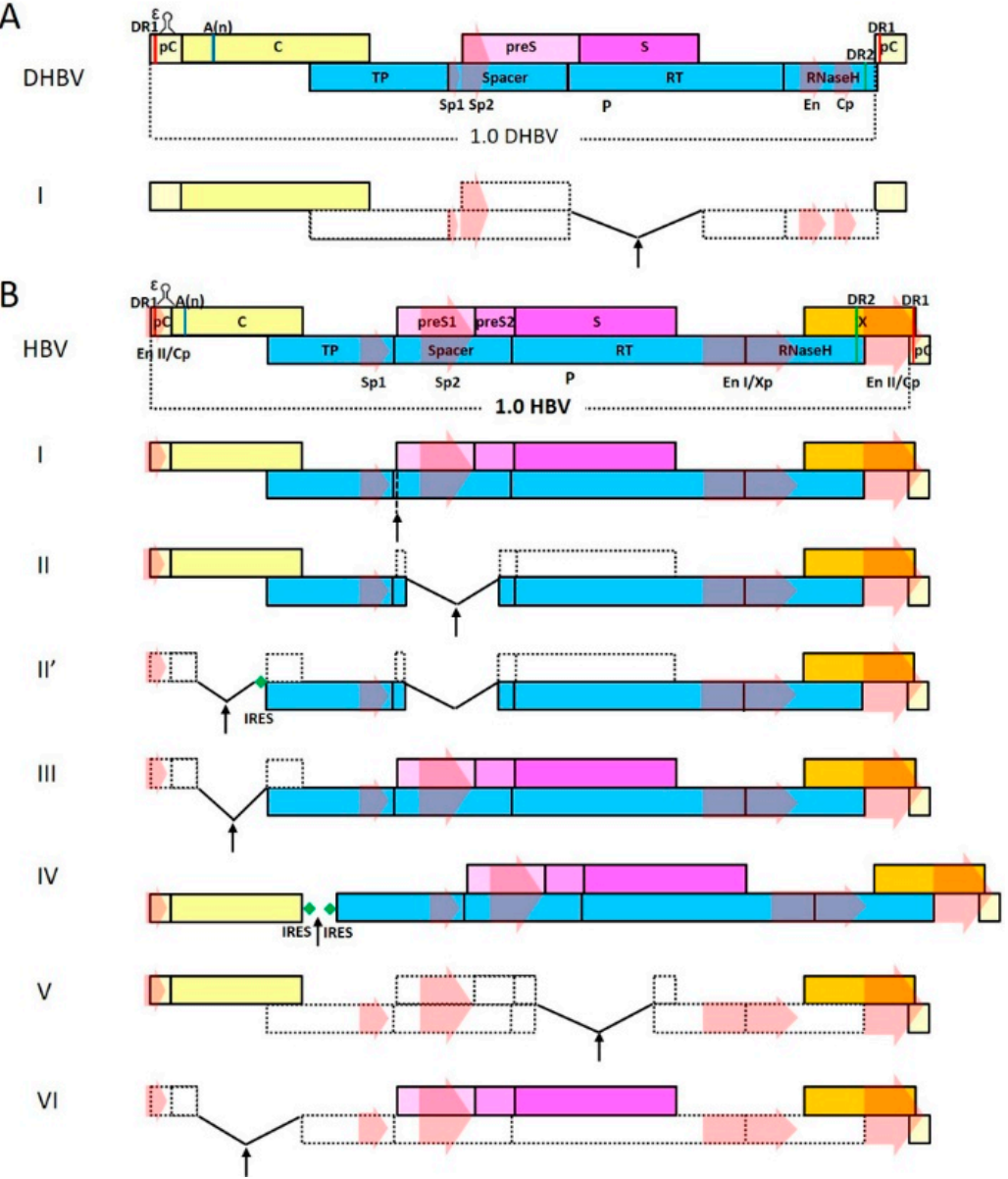

Figure 1. Schematic representation of genome organization of HBV and DHBV and major recombinant (D)HBV vector designs. Terminally-redundant wild-type genomes are shown to reflect the circularity and 1.0 copy of each genome is marked out beginning at the start codon of $\mathrm{preC}(\mathrm{pC}) / \mathrm{C}$ ORF. ORFs are represented by boxes and ORFs destroyed in recombinant vectors are depicted using dotted lines. Promoters (Cp, Sp1, Sp2, and Xp) and enhancers (En, EnI, EnII) are represented by arrows pointing in the direction of transcription. Cis elements required for replication and encapsidation are also depicted. $\varepsilon$, encapsidation signal. A(n), polyadenylation signal. DR, direct repeats. (A) Wild-type DHBV genome and recombinant DHBV design: I, cargo gene replaces S ORF in-frame and destroys the overlapping P ORF. (B) wild-type HBV genome and recombinant HBV designs: I, cargo gene is inserted in-frame with P ORF within spacer region, upstream of preS1 ORF. P ORF may or may not be terminated depending on cargo. II, cargo gene is inserted in a deletion in polymerase spacer in-frame with preS1/preS2 ORF, without terminating the overlapping P ORF. II', derivative of II. The cargo gene replaces the central part of prematurely-terminated C ORF, followed by IRES upstream of P ORF with a maximized deletion in the spacer region that retains polymerase activity but destroys preS1/preS2 ORF. III, the cargo gene replaces central part of C ORF and may or may not be expressly fused to the remaining $\mathrm{N}$-terminal of preC/C, depending on the design. IV, IRES units are introduced to separate de-overlapped $\mathrm{C}$ and $\mathrm{P}$ ORFs. No viral ORF is obliterated. $\mathrm{V}$, the cargo gene replaces $\mathrm{S}$ ORF in-frame and destroys the overlapping P ORF. VI, the cargo gene replaces the central and C-terminal of C ORF, destroying the overlapping P ORF. Arrows indicate insertion sites. Vector designs with obliterated $\mathrm{C}$ and/or P ORFs require trans-complementation of the obliterated proteins for genome replication. Vector designs with obliterated envelope ORFs require trans-complementation of envelope proteins for production of progeny virus. 
Mature, infectious hepadnavirus virions contain the rcDNA genome and enter hepatocytes through interactions between large surface antigens and specific cellular receptor(s). Once inside, the viral capsid releases its genome contents into nucleus, where rcDNA is converted into covalently-closed circular DNA (cccDNA) that then serves as a transcription template for all viral RNA species. Both core and viral polymerase are translated from the same transcript, termed pregenomic RNA (pgRNA), which also serves as a template for genome replication. Most notably, for wild-type viruses, nascent polymerase co-translationally binds to the epsilon signal at the $5^{\prime}$ terminal of its own pgRNA in cis, and initiates reverse transcription using an internal, conserved tyrosine residue as a primer for negative-strand DNA synthesis. A vital translocation step then follows, with the polymerase-primer "jumping" from the $5^{\prime}$ terminal to the $3^{\prime}$ terminal of pgRNA, which involves the DR1/DR2 direct repeat sequences at both termini. Packaging of the pgRNA/polymerase complex by viral core proteins is essential for productive genome replication and eventual formation of progeny rcDNA. Capsids containing newly-formed rcDNA then obtain host-derived membranes containing viral envelope proteins to produce progeny viruses and exit through budding at the ER. Alternatively, capsids are rerouted to the nucleus and the released rcDNA are converted into cccDNA to increase the level of transcription templates.

\section{Hepadnavirus-Specific Difficulties for the Design and Development of Viral Vectors}

Characteristic peculiarities in the genome organization and life cycle of hepadnaviruses pose specific difficulties and problems for efforts aimed at engineering recombinant hepadnavirus vectors.

First of all, genome sizes of wild-type viruses very likely represent the maximum limit that could be tolerated by the viral replication and packaging mechanisms. This has been demonstrated by in vitro experiments using artificially-created longer-than-wild-type genomes [17], and is possibly also reflected in a general lack of natural over-size insertion mutants reported in the literature. The viral capsid can also be expected to impose an intrinsic restriction on the size of genome that could be packaged within, along with the associated polymerase. Furthermore, studies of hepadnaviral reverse transcription mechanisms have revealed that efficiency of proper polymerase translocation giving rise to correct replication products deteriorates when the distance between $5^{\prime}$ and $3^{\prime}$ DRs exceeds the wild-type genome length $[17,18]$.

Secondly, although initiation of reverse transcription of pgRNA could be mediated in trans by polymerase translated from other mRNA, the efficiency has been shown to be far inferior to that initiated in cis by polymerase translated from pgRNA [19]. Such tight coupling of polymerase translation with genome replication dictates that recombinant genome needs to encode a functional polymerase for it to be able to replicate with a wild-type level of efficiency and subsequently produce applicable quantities of recombinant virions. Given that coding sequences of wild-type polymerase make up $\sim 75 \%$ of the hepadnavirus genome, very limited space is available for engineering purposes if polymerase ORF is to be left untouched, heavily restricting cargo capacity. On the other hand, obliterating polymerase ORF would markedly free up more space for cargo sequences, but at the expense of replication competence. 
Thirdly, orthohepadnaviruses encode an X protein (HBx) that has been shown to be capable of playing a myriad of functions in virus-host interactions in vitro and/or in vivo [20]. Most notably, HBx is apparently a key stimulator of both cccDNA-directed transcription and, indirectly via the regulation of pgRNA synthesis, genome replication [21]. HBx does not appear to be packaged into HBV virions and experiments in vitro have demonstrated that HBV mutants lacking functional HBx ORF could not establish or sustain productive infection in susceptible cells [22,23]. Therefore, for a recombinant HBV to be optimally active in infected cells, intact HBx ORF is most likely required. Fortunately, since the entire length of $\mathrm{HBx}$ is overlapping with other vital elements of HBV genome (Figure 1), HBx ORF can be easily left untouched in recombinant HBV vector design.

Intrinsic peculiarities of hepadnavirus virology not only impose the above challenges for the design and engineering of recombinant virus vectors, but they also make testing of these vectors technically difficult. For example, the envelopment of hepadnaviral capsids appears to be a highly-specific process that, in distinct contrast to some other enveloped viruses like poxviruses and lentiviruses, does not normally incorporate membrane proteins other than the corresponding hepadnaviral envelope proteins. This makes it highly difficult to create pseudotyped hepadnaviruses that could be tested on cells of non-liver origin. Consequently, testing of recombinant hepadnavirus vectors have to rely on hepatocytes that support infection by wild type hepadnavirus.

For the prototype avihepadnavirus DHBV, effective infection in vivo of ducklings and in vitro of either primary duck hepatocytes or the chicken hepatoma-derived LMH cell line have been commonly used $[3,15]$. For HBV, however, stably reproducible infection in vivo has only been demonstrated for certain higher primates, especially chimpanzees $[15,24]$, which are economically and ethically prohibitive for routine experiments. Alternatively, chimeric immunodeficient mice harboring human primary hepatocytes can be used to simulate HBV infection in vivo [25,26], but in the absence of normal immune functions, virus-host interactions are not fully reflected. In vitro, primary human and tree shrew hepatocytes [27], hepatoma-derived HepaRG cells [28] and, recently, liver cell lines stably transfected with the HBV receptor NTCP $\left(\mathrm{Na}^{+}\right.$-taurocholate cotransporting polypeptide) [29], have been used. Although these systems support HBV infection with varying efficiencies, so far only primary infection can be achieved, without demonstrable secondary infection by progeny viruses. For WHV, although woodchucks can be routinely infected using viruses prepared from naturally- or experimentally-infected animals, efficient production of infectious virus in vitro has yet to be achieved.

\section{Hepadnavirus-Derived Viral Vectors}

It was more than 25 years ago when the first work dealing with recombinant hepadnaviruses was published [30]. Since then, attempts at engineering usable hepadnavirus vectors have been made repeatedly, with varying degrees of success. Due to its obvious clinical relevance, most efforts have targeted HBV. This section will summarize historical and recent progresses by describing and comparing vector designs validated by sufficient experimental data (Table 1).

As discussed in the previous section, reverse transcription of hepadnaviral pgRNA is far more efficient if it is initiated in cis by polymerase translated from the same pgRNA. Most researchers, therefore, have opted to retain polymerase expression in their vector design in the hope of achieving higher replicative competence. Recombinant hepadnavirus designs are, therefore, divided into two categories according to whether functional polymerase is encoded by the vector or needs to be complemented in trans, and discussed respectively. 
Table 1. Listing and comparison of recombinant hepadnavirus vector design.

\begin{tabular}{|c|c|c|c|c|c|c|c|c|c|}
\hline Publication & $\begin{array}{l}\text { Virus } \\
\text { Base }\end{array}$ & $\begin{array}{c}\text { Required trans- } \\
\text { Complementation } 1\end{array}$ & $\begin{array}{l}\text { Cargo Insertion Site and } \\
\text { Insertion Strategy }\end{array}$ & $\begin{array}{l}\text { Tested } \\
\text { Cargo(s) } \\
\text { (Length) }\end{array}$ & $\begin{array}{l}\text { Replication } \\
\text { Evidence }\end{array}$ & $\begin{array}{l}\text { Replication } \\
\text { Efficiency }\end{array}$ & $\begin{array}{l}\text { Virion Formation } \\
\text { Evidence }^{2}\end{array}$ & $\begin{array}{l}\text { Virion Formation } \\
\text { Efficiency }\end{array}$ & $\begin{array}{c}\text { Virion } \\
\text { Infectivity } \\
\text { Evidence }\end{array}$ \\
\hline \multicolumn{10}{|c|}{ Recombinant vectors that express functional polymerase } \\
\hline $\begin{array}{l}\text { Chang et al., } \\
1990[30]\end{array}$ & DHBV & $\mathrm{preS} / \mathrm{S}$ & $\begin{array}{l}\text { Cargo ORF inserted in-frame in } \\
\text { Pol spacer between preS and S } \\
\text { with own ATG but no stop codon }\end{array}$ & $\begin{array}{l}\text { Protein A } \\
\quad(369)\end{array}$ & $\begin{array}{l}\text { EPA, Southern } \\
\text { blot }\end{array}$ & Comparable & N.D. & N.D. & N.D. \\
\hline $\begin{array}{l}\text { Chaisomchit et al., } \\
\quad 1997 \text { [31] }\end{array}$ & $\mathrm{HBV}$ & None & $\begin{array}{l}\text { Cargo ORF inserted in-frame in } \\
\text { Pol spacer between Sp1 and } \\
\text { preS1 start codon with own start } \\
\text { but no stop codon }\end{array}$ & HIV Tat (267) & EPA & $\begin{array}{l}\text { Severely } \\
\text { reduced }\end{array}$ & $\begin{array}{l}\text { Capture by S antibodies } \\
\text { followed by Southern blot }\end{array}$ & Severely reduced & N.D. \\
\hline $\begin{array}{l}\text { Wang et al., } \\
2002 \text { [32] }\end{array}$ & $\mathrm{HBV}$ & C & $\begin{array}{c}\text { Cargo ORF replaced C ORF } \\
\text { between } \varepsilon / A(n) \text { and Pol start } \\
\text { codon, fused to remaining } \\
\text { N-terminal of } C\end{array}$ & Flag (48) & Southern blot & $\begin{array}{l}\text { Severely } \\
\text { reduced }\end{array}$ & $\begin{array}{l}\text { Density gradient } \\
\text { ultracentrifuge followed by } \\
\text { Southern blot and PCR }\end{array}$ & N.D. & PHH \\
\hline $\begin{array}{l}\text { Yoo et al., } \\
2002[33]\end{array}$ & $\mathrm{HBV}$ & C & $\begin{array}{l}\text { Cargo ORF replaced C ORF } \\
\text { between } \varepsilon / A(n) \text { and Pol } \\
\text { start codon }\end{array}$ & GFP & $\begin{array}{c}\text { EPA, } \\
\text { Southern blot }\end{array}$ & $\begin{array}{l}\text { Severely } \\
\text { reduced }\end{array}$ & $\begin{array}{c}\text { Density gradient } \\
\text { ultracentrifuge and capture } \\
\text { by } S \text { antibodies followed } \\
\text { by Southern blot }\end{array}$ & N.D. & PHH, HepG2 \\
\hline $\begin{array}{l}\text { Deng et al., } \\
2009 \text { [34] } \\
\text { Wang et al., } \\
2014 \text { [35] }\end{array}$ & $\mathrm{HBV}$ & C & $\begin{array}{l}\text { Cargo ORF replaced C ORF } \\
\text { between } \varepsilon / A(n) \text { and Pol start } \\
\text { codon, fused to remaining } \\
\text { N-terminal of C. Kozak } \\
\text { sequences of Pol } \\
\text { were optimized. }\end{array}$ & Peptide (180) & Southern blot & Increased & $\begin{array}{l}\text { Density gradient } \\
\text { ultracentrifuge followed by } \\
\text { dot blot }\end{array}$ & Reduced & PTH \\
\hline $\begin{array}{l}\text { Wang et al., } \\
2013 \text { [36] }\end{array}$ & $\mathrm{HBV}$ & None & $\begin{array}{l}\text { Cargo ORF inserted between } \\
\text { separated C and Pol ORF with } \\
\text { intervening short IRES }\end{array}$ & $\begin{array}{l}\text { BsdR (399) } \\
\text { GFP (720) }\end{array}$ & $\begin{array}{c}\text { EPA, } \\
\text { Southern blot }\end{array}$ & $\begin{array}{l}\text { Comparable } \\
\text { to severely } \\
\text { reduced } \\
\text { depending } \\
\text { on cargo }\end{array}$ & $\begin{array}{l}\text { Density gradient } \\
\text { ultracentrifuge followed by } \\
\text { Southern blot }\end{array}$ & $\begin{array}{l}\text { Comparable to } \\
\text { severely reduced } \\
\text { depending } \\
\text { on cargo }\end{array}$ & HepaRG \\
\hline $\begin{array}{l}\text { Hong et al., } \\
2013 \text { [37] }\end{array}$ & $\mathrm{HBV}$ & preS1/preS2/S & $\begin{array}{l}\text { Cargo sequences replaced } 384 \text { bp } \\
\text { of Pol spacer (preS1/preS2) } \\
\text { in-frame with preS1, without } \\
\text { terminating Pol ORF. Start codon } \\
\text { of preS1 mutated. }\end{array}$ & $\begin{array}{l}\text { HIV Tat (207) } \\
\text { DsRed (678) } \\
\text { shRNA } \\
\text { cassette (294) }\end{array}$ & Southern blot & $\begin{array}{l}\text { Comparable } \\
\text { to reduced } \\
\text { depending } \\
\text { on cargo }\end{array}$ & $\begin{array}{l}\text { Capture by preS1 mAb } \\
\text { followed by Southern blot }\end{array}$ & $\begin{array}{l}\text { Comparable to } \\
\text { reduced } \\
\text { depending } \\
\text { on cargo }\end{array}$ & PTH \\
\hline $\begin{array}{l}\text { Bai } \text { et al., } \\
\text { (submitted) }\end{array}$ & $\mathrm{HBV}$ & $\begin{array}{c}\mathrm{C} \\
\mathrm{preS1/preS2/S}\end{array}$ & $\begin{array}{l}\text { Cargo sequences replaced C ORF } \\
\text { between } \varepsilon / \mathrm{A}(\mathrm{n}) \text { and Pol start } \\
\text { codon. Short IRES placed before } \\
\text { Pol start codon and } 384 \text { bp of Pol } \\
\text { spacer (preS1/preS2), same as } \\
\text { above, deleted. C ORF } \\
\text { prematurely terminated. }\end{array}$ & $\begin{array}{c}\text { ZeoR (375) } \\
\text { NanoLuc } \\
(522 / 606)^{4} \\
\text { DsRed (678) } \\
\text { GFP (747) } \\
\text { shRNA } \\
\text { cassette (294) }\end{array}$ & Southern blot & $\begin{array}{l}\text { Comparable } \\
\text { to reduced } \\
\text { depending } \\
\text { on cargo }\end{array}$ & $\begin{array}{l}\text { Capture by preS1 mAb } \\
\text { followed by Southern blot }\end{array}$ & $\begin{array}{l}\text { Comparable to } \\
\text { reduced } \\
\text { depending } \\
\text { on cargo }\end{array}$ & PTH \\
\hline
\end{tabular}


Table 1. Cont.

\begin{tabular}{|c|c|c|c|c|c|c|c|c|c|}
\hline Publication & $\begin{array}{l}\text { Virus } \\
\text { Base }\end{array}$ & $\begin{array}{l}\text { Required trans- } \\
\text { Complementation }{ }^{1}\end{array}$ & $\begin{array}{l}\text { Cargo Insertion Site and } \\
\text { Insertion Strategy }\end{array}$ & $\begin{array}{l}\text { Tested } \\
\text { Cargo(s) } \\
\text { (Length) }\end{array}$ & $\begin{array}{l}\text { Replication } \\
\text { Evidence }\end{array}$ & $\begin{array}{l}\text { Replication } \\
\text { Efficiency }\end{array}$ & $\begin{array}{l}\text { Virion Formation } \\
\text { Evidence }^{2}\end{array}$ & $\begin{array}{l}\text { Virion Formation } \\
\text { Efficiency }\end{array}$ & $\begin{array}{l}\text { Virion } \\
\text { Infectivity } \\
\text { Evidence }\end{array}$ \\
\hline \multicolumn{10}{|c|}{ Recombinant vectors that do not express functional polymerase } \\
\hline $\begin{array}{l}\text { Chaisomchit et al., } \\
\quad 1997 \text { [31] }\end{array}$ & HBV & Pol & $\begin{array}{l}\text { Cargo ORF inserted in-frame in } \\
\text { Pol spacer between Sp1 and } \\
\text { preS1 start codon with own start } \\
\text { and stop codon }\end{array}$ & ZeoR (372) & $\mathrm{EPA}$ & $\begin{array}{l}\text { Severely } \\
\text { reduced }\end{array}$ & N.D. & N.D. & N.D. \\
\hline $\begin{array}{l}\text { Protzer et al., } \\
1999[17]\end{array}$ & DHBV & $\begin{array}{l}\text { Pol } \\
\text { preS/S }\end{array}$ & $\begin{array}{l}\text { Cargo ORF replaced } 558 \text { bp of } \mathrm{S} \\
\text { ORF in-frame }\end{array}$ & $\begin{array}{l}\text { GFP (733) } \\
\text { Duck } \\
\text { IFN (591) }\end{array}$ & N.D. & N.D. & $\begin{array}{c}\text { Density gradient } \\
\text { ultracentrifuge followed by } \\
\text { dot blot }\end{array}$ & N.D. & $\mathrm{PDH}$ \\
\hline Ibid. & HBV & $\begin{array}{c}\text { Pol } \\
\mathrm{preS} 1 / \mathrm{preS} 2 / \mathrm{S}\end{array}$ & $\begin{array}{l}\text { Cargo ORF replaced } 939 \mathrm{bp} \text { of } \mathrm{S} \\
\text { ORF in-frame }\end{array}$ & GFP (733) & N.D. & N.D. & Ibid. & N.D. & PHH \\
\hline $\begin{array}{l}\text { Untergasser et al., } \\
\quad 2004 \text { [38] }\end{array}$ & HBV & All HBV ORFs & $\begin{array}{l}\text { Cargo ORF replaced } 939 \mathrm{nt} \text { of } \mathrm{S} \\
\text { ORF in-frame. All other HBV } \\
\text { ORFs are prematurely } \\
\text { terminated by mutation. Some } \\
\text { constructs replaced } 311 \mathrm{nt} \text { of } \\
\text { SP2 with exogenous promoters } \\
\quad 366 \text { nt or } 575 \mathrm{nt} \text { long. }\end{array}$ & $\begin{array}{l}\text { GFP (733) } \\
\text { RLuc (942) }\end{array}$ & Southern blot & N.D. & Ibid. & Comparable & PHH \\
\hline Liu et al., 2013 [39] & HBV & All HBV ORFs & $\begin{array}{l}\text { Cargo ORF replaced S ORF } \\
\text { in-frame. All other HBV ORFs } \\
\text { are prematurely terminated or } \\
\text { nulled by mutation. }\end{array}$ & $\begin{array}{l}\text { GFP } \\
\text { RFP }\end{array}$ & Southern blot & Reduced & N.D. & N.D. & HepaRG \\
\hline $\begin{array}{l}\text { Nishitsuji et al., } \\
2015[40]\end{array}$ & HBV & $\begin{array}{c}\text { Pol } \\
\text { C }\end{array}$ & $\begin{array}{l}\text { Cargo ORF with own start and } \\
\text { stop codons replaced } 562 \mathrm{nt} \text { of } C \\
\text { ORF downstream of } \varepsilon / \mathrm{A}(\mathrm{n}) \text { and } \\
\text { the N-terminal of P ORF }\end{array}$ & $\begin{array}{l}\text { NanoLuc } \\
(513)\end{array}$ & N.D. & N.D. & $\begin{array}{l}\text { Density gradient } \\
\text { ultracentrifuge followed by } \\
\text { Southern blot }\end{array}$ & N.D. & $\begin{array}{l}\text { PXB } \\
\text { NTCP cell } \\
\text { lines }\end{array}$ \\
\hline \multicolumn{10}{|c|}{$\begin{array}{l}{ }^{1} \text { core and polymerase are absolutely required for genome replication; envelope proteins (DHBV preS/S and HBV preS1/preS2/S) are only required for virion formation. }{ }^{2} \text { due to } \\
\text { secretion of non-enveloped capsids by transfected cells [35-37,40], detection of viral DNA in transfection supernatants without virion-specific separation or enrichment step(s) is } \\
\text { considered only evidence of replication. }{ }^{3} \text { despite early controversies, human hepatoma cells lines, such as HepG2 and Huh-7, are currently generally accepted as not susceptible to } \\
\text { HBV infection. }{ }^{4} \text { two forms, one intracellular and one secreted, were tested. } \varepsilon \text {, signal on pre-genomic RNA. A(n), polyadenylation signal. EPA, endogenous polymerase activity assay, } \\
\text { which measures polymerase-catalyzed incorporation of isotope-labelled nucleotides into progeny genomes within viral capsids. PHH, PTH, and PDH refer to primary human, tupaia, } \\
\text { and duck hepatocytes, respectively. PXB, hepatocytes prepared from chimeric mouse harboring human primary hepatocytes. N.D., not done or not shown. }\end{array}$} \\
\hline
\end{tabular}




\subsection{Vectors that Encode Functional Polymerase}

Characterization of hepadnavirus polymerase functions revealed early on that it is made up of four structurally and functionally distinct domains: an N-terminal TP (terminal priming) domain that is responsible for catalyzing the priming of negative strand DNA synthesis after binding to pgRNA epsilon in cis, a spacer or tether domain that joins the neighboring domains, an RT (reverse transcription) domain that synthesizes both negative and positive strands of the progeny viral genome, and an RH (RNaseH) domain that degrades pgRNA after negative-strand DNA is synthesized [3]. Among the polymerase domains, the spacer is the least conserved and predicted to be the least structurally ordered. Most likely, it only functions as a physical linker or hinge.

\subsubsection{Vectors that Use Polymerase Spacer Region for Cargo Insertion}

While examining the ability of DHBV polymerase to tolerate mutations and insertions at various locations, Chang et al. found that insertion of coding sequences for bacterial protein A (369 nt) without termination codon in-frame into the spacer region, between preS and $S$ in the overlapping ORF, did not abolish polymerase activity and self-sufficient replication of the resultant recombinant genome [30]. The cargo ORF carried its own start codon, making it theoretically possible for preS/S mRNA and probably also pgRNA to translate protein A fused to the C-terminal half of polymerase, in addition to full-length polymerase with protein A sequences embedded in the spacer region, but this former type of fusion protein was apparently not translated to detectable levels in transfected cells. Since the preS/S ORF is interrupted by cargo insertion, the recombinant genome would require trans-complemented envelope proteins to form mature progeny virions. Although this early work was not a study devoted to recombinant HBV and recombinant virion production was not tested, the results showed that polymerase spacer is a viable cargo insertion site for engineering self-replicating recombinant hepadnavirus.

The first comprehensive study of recombinant hepadnavirus was published by Chaisomchit et al. in 1997 [31] with a design scheme similar to the work by Chang et al. The authors proposed recombinant HBV as "more efficient means for gene delivery to the liver" compared to retroviral and adenoviral vectors. They first tested the possibility by inserting coding sequences for HIV Tat protein (267 nt) without a stop codon in-frame into the polymerase spacer, between the Sp1 promoter and preS1 start codon in the overlapping ORF (Figure 1B, design I). This insertion site was located more upstream and closer to the TP domain compared to the protein A insertion site in the previous work. HBV polymerase with Tat sequences inserted in spacer was functional and replicated recombinant genome at efficiencies that were $1.5 \%-4 \%$ of wild-type HBV. As only P ORF is affected, the recombinant genome does not require trans-complementation of viral structural proteins and enveloped recombinant virions could be detected in transfection supernatants, but only at very low levels. Infectivity of recombinant virions was not tested. Tat-induced transcription activation of promoters could be detected in transfected cells, and it was shown that Tat fused to C-terminal part of polymerase could be translated from Sp1 transcribed mRNA. This pioneering study demonstrated with compelling evidence that polymerase spacers could tolerate fairly long insertions at the cost of replication efficiency.

Both of these two early studies used similar design that inserted cargo genes into polymerase spacer of wild-type genomes. Our lab also made an attempt to harness the polymerase spacer as an insertion site to develop recombinant HBV vectors for hepatocyte-specific delivery of reporter and functional genes. However, instead of wild-type HBV, we based our design on a clinically-isolated, highly-replicative HBV mutant that harbors a large in-frame deletion of $207 \mathrm{nt}$ in the polymerase spacer [37]. The mutant does not encode functional envelope proteins due to the partial loss of preS1 ORF and non-sense mutations in S ORF, and the polymerase contains a 69 amino acid deletion in the spacer region. However, the mutant replicates more efficiently than the wild-type, and when trans-complemented with functional envelope proteins, produces mature enveloped progeny viruses also more efficiently than the wild-type. We inserted terminated ORF encoding the N-terminal activation domain of HIV Tat (207 nt) into the deletion in the polymerase spacer, but unlike the 
previous two studies, the inserted ORF was in-frame with preS1 so as not to be expressed fused to polymerase, and multiple synonymous mutations were used to avoid terminating the overlapping P ORF (Figure 1B, design II). The recombinant HBV replicated and produced progeny virions with efficiencies comparable to the wild-type, and Tat expression driven by $\mathrm{Sp} 1$ could be detected using reporter assay. The polymerase spacer deletion in the mutant was then maximized to increase cargo capacity and we obtained a vector with a $384 \mathrm{nt}$ in-frame deletion that replicated as efficiently as the parental mutant. The vector could tolerate insertions of up to $675 \mathrm{nt}$ and still retain wild-type-level replicative competence, as long as P ORF is not interrupted. We demonstrated that recombinant HBV carrying synonymously-mutated sequences encoding DsRed infected PTH with high efficiency. Moreover, we showed that the vector could carry and express functional RNA in infected PTH, which was the first report of recombinant HBV delivering non-protein cargo. Naturally, the major limitation of this design is that cargo sequences must not introduce stop codons in P ORF, which is often difficult and sometimes impossible.

\subsubsection{Vectors that Use Core Region for Cargo Insertion}

Inserting cargo sequences into polymerase spacer while keeping the resultant polymerase active is inherently difficult. Consequently, other published designs in this category chose to avoid changing P ORF. On the hepadnaviral genome, all cis-acting sequence elements required for genome replication and packaging are clustered closely together between the C-terminal part of polymerase and N-terminal of core, with the remaining part of polymerase taking up almost all of the rest of genome space (Figure 1). The only segment of the genome that is apparently replaceable without affecting P ORF or cis elements is the middle part of C ORF ( $350 \mathrm{nt})$ between epsilon packaging/polyadenylation signals and the start codon of P ORF.

In an attempt to test recombinant $\mathrm{HBV}$ as a potential liver-targeting delivery vector, Wang et al. examined a series of HBV deletion mutants, one of which allowed the replacement of the central part of C ORF with a short terminated ORF encoding Flag tag (48 nt) that was inserted in-frame with the preceding N-terminal of C ORF (Figure 1B, design III) [32]. The recombinant genome could replicate at levels much lower than wild type when trans-complemented with core, and produced recombinant virions that infected $\mathrm{PHH}$ with low efficiency. The Flag tag is expected to be expressed as a C-terminal fusion to the remaining $\mathrm{N}$-terminal of e and $\mathrm{c}$ antigens. However, extending the Flag tag with C-terminal addition of full-length or truncated GFP sequences resulted in a loss of replicative competence. In a similar study roughly coinciding with this work, Yoo et al. replaced the same part of C ORF with GFP-encoding sequences ( 720 nt), without specifying whether the insertion was in-frame with $C$ or whether it carried its own start and stop codons. Replication efficiency of this recombinant $\mathrm{HBV}$ was about $3 \%$ of wild-type $\mathrm{HBV}$ in the presence of trans-complemented core expression [33]. However, no marked increase in genome size was observed in Southern blot as should be expected. Enveloped virions were demonstrated in co-transfection supernatants at significantly reduced levels compared to the wild-type. Recombinant virions infected primary human hepatocytes and questionably, also HepG2, and resulted in detectable fluorescence in infected cells.

These two studies demonstrated that the central part of C ORF is also a viable choice as cargo insertion site, but the reported insertions severely affected replication competence. In wild-type $\mathrm{HBV}$, both core and polymerase are translated from pgRNA. Multiple mechanisms have been shown to be involved in translation initiation of the downstream P ORF, including leaky scanning and ribosome re-initiation [41], and sequences upstream of polymerase start codon significantly affect the translation efficiency of polymerase and consequently, replication efficiency of the genome. In light of this, inefficient expression of polymerase might be responsible, at least partially, for the low replicative competence observed in the two studies discussed above. In a study aimed at liver-targeting delivery of immunogenic peptides, Deng et al. attempted to alleviate this problem by optimizing sequences surrounding HBV polymerase start codon according to Kozak's rules [34], while replacing the upstream central part of C ORF with sequences encoding a polyepitope peptide (180 nt) in a fashion 
similar to the design of Wang et al. above. The recombinant HBV apparently replicated better than wild-type HBV in the presence of a trans-complemented core, and in a follow-up study, mature virions infectious for primary tupaia hepatocytes (PTH) were demonstrated to be produced at levels lower than the wild-type [35]. Expression of the cargo peptide, however, was only shown using plasmid or recombinant adenovirus as delivery vectors [34,35].

An alternative approach to enhancing polymerase translation is to make it independent of upstream sequences by inserting an internal ribosome entry site (IRES) before its start codon. In the work by Wang et al. [35], the overlapping part of C/P ORFs was duplicated to create non-overlapping $\mathrm{C}$ and P ORFs. ORF encoding blastidicin resistance protein (BsdR, $399 \mathrm{nt}$ ) or GFP (720 nt) with a termination codon at the $3^{\prime}$ end was then inserted between C and P ORFs, and short IRES units were used to separate the three (Figure 1B, design IV). Since all viral ORFs are still present, such a design requires no trans-complementation of wild-type HBV proteins. Recombinant HBV harboring the shorter BsdR replicated and produced progeny virions with efficiencies generally comparable to wild-type HBV, but insertion of the longer GFP resulted in severely reduced replication and nearly undetectable progeny virus secretion. As duplication of part of C ORF increases the genome size beyond that of the wild-type, even without cargo insertion, inability to harbor long insertions is not surprising. Infectivity of the recombinant virus was then demonstrated using HepaRG cells. An analogous strategy has been used in our lab (submitted) to improve the previously-described vector with a maximized deletion in polymerase spacer [37]. A short artificial IRES was placed before the start codon of $\mathrm{P}$ ORF containing the maximized deletion in spacer, and cargo sequences replaced the central part of C ORF (Figure 1B, design $\mathrm{II}^{\prime}$ ). Unlike the above studies, cargo protein genes carried own start and stop codons and upstream remaining C ORF was terminated to avoid expressing cargo genes as fusions to the remaining N-terminal of core. Recombinant HBV harboring fluorescent and bioluminescent reporters of 375-747 nt replicated, in the presence of trans-complemented core, with varying efficiencies that were mostly comparable to the wild-type, depending on the length and type of the insertion. Enveloped progeny viruses were obtained by providing wild-type core and envelope proteins in trans to recombinant genomes and infectivity of recombinant viruses harboring protein or RNA genes was demonstrated using PTH. Compared to its parental vector, the switch to C ORF for insertion allowed freer choice of cargo sequences, while the inheritance of replication-enhancing deletion in polymerase ORF and isolation of polymerase translation through introduction of IRES provided acceptable replication efficiencies for most of the tested cargos.

\subsection{Vectors that Do Not Encode Functional Polymerase}

Theoretically, since all cis-acting sequence elements required for genome replication and packaging are located between the C-terminal part of the polymerase and N-terminal of the core (Figure 1), cargo sequences can be inserted anywhere, or replace any segment(s), on the rest of hepadnavirus genome, if polymerase expression does not need to be retained by the recombinant vector. Such vectors would have maximal capacity for harboring cargo sequences. However, all except one of the few reports on vectors belonging to this category chose to use the $S$ or P ORF for cargo insertion, fairly distant from those cis-acting elements, which might be beneficial by minimizing interference of their functions by cargo sequences.

In their pioneering work on recombinant $\mathrm{HBV}$ vectors, Chaisomchit $e t$ al. also tested a non-replicative version of their design by replacing the un-terminated in-frame Tat insertion in polymerase spacer with a terminated in-frame insertion of ZeoR (372 nt) (Figure 1B, design I) [31]. Self-sufficient replication of the recombinant genome was expectedly obliterated, and even with trans-complemented polymerase, replication was only $1.5 \%-3 \%$ of wild-type $\mathrm{HBV}$, which is similar to the replicative vector with non-terminated Tat insertion. Virion formation and infection were not examined.

Later, in the hope of achieving delivery of therapeutic genes to hepatocytes, Protzer et al. developed DHBV and HBV vectors that have most of the S ORF replaced with GFP or duck interferon coding sequences in-frame (Figure 1A, design I and Figure 1B, design V) [17]. The overlapping $P$ 
ORF is prematurely terminated by the cargo sequences. Recombinant viruses infectious for primary duck or human hepatocytes (PDH and PHH) could be obtained from transfection supernatants, if trans-complemented with both polymerase and envelope proteins. Notably, the authors showed that a recombinant DHBV-expressing duck interferon was able to inhibit co-infecting wild-type DHBV in $\mathrm{PDH}$ infection assay, which constituted the first demonstration of the therapeutic value of recombinant hepadnavirus. Following up on this work, Untergasser et al. attempted to improve the vector from the safety perspective of potential gene therapy applications by prematurely terminating all viral ORFs in the vector so that the recombinant HBV would express only the cargo gene product [38]. Since there was no significant change to the vector design, recombinant HBV harboring GFP or renilla luciferase (942 nt) were obtained when trans-complemented wild-type HBV proteins, and the virions infected $\mathrm{PHH}$ and expressed the cargo genes. In addition, stronger, exogenous promoters were tested in replacement of Sp2 in the hope of enhancing cargo gene expression, but although recombinant viruses infectious for $\mathrm{PHH}$ were produced, enhanced expression was not demonstrated using infection assay. Similar design was used by Liu et al. in a later study also aimed at liver-targeting delivery of therapeutic genes [39]. The authors replaced S ORF in-frame with sequences encoding GFP or RFP, and observed reduced replication compared to wild type HBV in the presence of trans-complemented HBV proteins. GFP expression by recombinant virions in infected HepaRG was demonstrated.

Recently, Nishitsuji et al. [40] reported a system allowing quantitative detection of HBV infection in vitro based on a polymerase-negative design of recombinant $\mathrm{HBV}$ that uses C ORF for cargo insertion, instead of polymerase or S ORF, as done in the previous designs in this category. However, in contrast to vectors that use C ORF as insertion site in the first category, they replaced the entire C ORF downstream of epsilon packaging/polyadenylation signals (562 nt), including the part overlapping with the N-terminal of P ORF, thus destroying polymerase expression (Figure 1B, design VI). Recombinant HBV harboring the NanoLuc reporter (513 nt) could be produced when trans-complementation of core and polymerase were provided and infection of human hepatocytes and NTCP-transfected hepatoma cell lines was demonstrated.

\subsection{Comparison of Vector Designs from the Perspective of Potential Applications}

Potential in vitro applications of recombinant hepadnavirus vectors include the study of fundamentals of hepadnavirus life cycle, most notably entry into target cells and formation of initial cccDNA from the incoming virus genome. At the same time, reporter-expressing recombinant hepadnaviruses would facilitate the development of drug screening and evaluating systems. In vivo, recombinant hepadnaviruses could form the basis of hepatocyte-targeting therapeutic interventions for liver-afflicting conditions, including HBV-related and non-HBV-related hepatitis, cirrhosis, and HCC, as well as life-threatening diseases not directly involving liver, such as type I diabetes. Reporter-expressing recombinant $\mathrm{HBV}$ would be useful for characterizing hepatotropism, sustenance, and biosafety of such therapeutics before in vivo applications could be attempted.

Different applications of recombinant virus vectors sometimes have different requirements regarding the vectors, in addition to functions of the cargo gene. For instance, for therapeutic interventions targeting chronic hepatitis B patients using recombinant HBV expressing interferon or HBV-targeting siRNA precursors, continuous high activity of a recombinant virus is only desirable while wild-type HBV is active in co-infected hepatocytes, but not thereafter. In contrast, sustained activity of recombinant HBV capable of surviving hepatocyte propagation and turnover, regardless of the presence or absence of wild-type HBV, is desired when, for example, using insulin-expressing recombinant $\mathrm{HBV}$ for treating type I diabetes.

Features of the recombinant hepadnavirus vector designs reviewed above are summarized in Table 2 with a focus on their capabilities of self-sufficient replication and progeny virus production. Recombinant hepadnaviruses encoding both functional core and polymerase proteins [31,36,37] are expected to be able to replicate their genomes and expand intranuclear cccDNA pools resulting in sustained high expression of cargo genes in infected cells, irrespective of wild-type 
co-infection. Consequently, such vectors would persist in infected hepatocytes and are, therefore, ideal for in vivo applications targeting non-HBV-related life-long diseases, and for studies where highly-sensitive detection of infection is desired. Progeny recombinant viruses will also be produced if core- and polymerase-producing recombinant viruses also encode functional envelope proteins [31,36]. This would theoretically allow secondary infection by progeny recombinant viruses of surrounding susceptible cells, further enhancing the level and continuity of cargo gene expression.

Table 2. Comparison of recombinant hepadnavirus vector designs.

\begin{tabular}{|c|c|c|c|}
\hline $\begin{array}{l}\text { Representative } \\
\text { Publication(s) }\end{array}$ & $\begin{array}{l}\text { Obliterated } \\
\text { ORF(s) }\end{array}$ & $\begin{array}{l}\text { cccDNA Pool } \\
\text { Expansion }^{1}\end{array}$ & $\begin{array}{l}\text { Progeny Virus } \\
\text { Production }^{2}\end{array}$ \\
\hline $\begin{array}{c}\text { Chaisomchit et al., } 1997 \text { [31] } \\
\text { Wang et al., } 2013 \text { [36] }\end{array}$ & None & Self-sufficient & Self-sufficient \\
\hline Hong et al., 2013 [37] & $S$ & Self-sufficient & Requires help \\
\hline $\begin{array}{l}\text { Wang et al., } 2002 \text { [32] } \\
\text { Yoo et al., } 2002 \text { [33] } \\
\text { Deng et al., } 2009 \text { [34] } \\
\text { Wang et al., } 2014 \text { [35] }\end{array}$ & $\mathrm{C}$ & Requires help & Requires help \\
\hline Bai et al. (submitted) & $\mathrm{C} / \mathrm{S}$ & Requires help & Requires help \\
\hline Chaisomchit et al., 1997 [31] & $\mathrm{P}$ & Requires help & Requires help \\
\hline $\begin{array}{l}\text { Protzer et al., } 1999 \text { [17] } \\
\text { Chang et al., } 1990 \text { [30] }\end{array}$ & $\mathrm{P} / \mathrm{S}$ & Requires help & Requires help \\
\hline Nishitsuji et al., 2015 [40] & $\mathrm{P} / \mathrm{C}$ & Requires help & Requires help \\
\hline $\begin{array}{l}\text { Untergasser et al., } 2004 \text { [38] } \\
\text { Liu et al., } 2013 \text { [39] }\end{array}$ & All & Requires help & Requires help \\
\hline $\begin{array}{l}1 \text { vectors with functional } \mathrm{C} \text { and } \\
\text { additional cccDNA in infected ce } \\
\text { retaining all functional viral ORFs } \\
\text { progeny recombinant viruses, } \\
\text { Requires help: trans-complementa } \\
\text { indicated functions. }\end{array}$ & $\begin{array}{l}\text { Fs are expecte } \\
\text { ch would, in t } \\
\text { pected to be at } \\
\text { vould in turn } \\
\text { obliterated pr }\end{array}$ & $\begin{array}{l}\text { able to replicate } \\
t \text { in higher cargo } \\
\text { icate self-sufficier } \\
\text { n infection of ac } \\
\text { a co-infecting wil }\end{array}$ & $\begin{array}{l}\text { ficiently and form } \\
\text { pression. }{ }^{2} \text { vectors } \\
\text { produce infectious } \\
\text { l susceptible cells } \\
\text { virus is required for }\end{array}$ \\
\hline
\end{tabular}

Loss of functional core and/or polymerase expression makes the majority of recombinant vectors incapable of replication, and consequently, progeny production, without co-infecting wild-type virus (Table 2). These vectors would likely persist with low activity and no expansion in mono-infected cells, but would start replication and progeny virus production, giving rise to enhanced cargo gene expression and expanded infection by recombinant virus, if the infected cells are to be super-infected with wild-type virus. Activity of recombinant virus will recede along with wild-type virus, if and when the latter is under control. Such activation by the wild-type makes these vectors ideal for therapeutic applications targeting infection by wild-type viruses.

\section{Future Perspectives on Recombinant Hepadnavirus Vector Design}

Minimal requirements for hepadnavirus genome replications include cis elements on pgRNA (Figure 1), functional core in cis or in trans, and functional polymerase preferably expressed in cis. Designs that do not retain functional polymerase on the recombinant genome theoretically would allow much freer choice of cargo length and insertion site. However, published studies in this category have not demonstrated such potential, and are generally limited to using fairly short cargo genes to replace viral ORF (Table 1). It is possible that future work on such vectors will liberate additional viral genome space and sites for cargo insertions, and enable the design of recombinant viruses harboring larger genes or multiple small genes to provide better or more complex functionalities.

Recombinant hepadnavirus designs that retain functional polymerase have inherently limited capacity for cargo insertions. Even with non-inactivating deletions in polymerase spacer [37], 
$600-700 \mathrm{nt}$ is very likely the maximum cargo length that is practical for HBV. The capacity will be further reduced if functional core is also to be retained [31,36]. However, the relative ease of recombinant virus production and expected higher expression of cargo genes in infected cells compared to polymerase-negative designs make such designs a favored choice in most cases. Finding or engineering small-sized cargo genes with experimentally- or clinically-important functions will be the key to making these vector designs more relevant to the field.

\section{Future Perspectives on Applications of Recombinant Hepadnavirus Vector}

Work on developing recombinant hepadnavirus vectors has been going on for two decades and there have been more than ten designs with varying degrees of similarity and innovation (Table 1). Some of the studies characterized the cargo capacity, replication, progeny virus production and infectivity in fairly great detail and convincingly demonstrated the usability of the corresponding vector, at least when used with the tested cargo. A couple of studies went further and showed the huge potential of such vectors for possible therapeutic applications in vivo [17,37].

Admittedly, compared to other more commonly used recombinant viral vector systems, such as retrovirus/lentivirus, poxvirus, adenovirus, and adeno-associated virus vectors, progress in the development and application of recombinant hepadnaviruses both in vivo and in vitro has been much slower and less fruitful. Nevertheless, lack of strict hepatotropism makes the other recombinant virus vectors intrinsically inferior to hepadnavirus vectors for hepatocyte-targeting applications. Moreover, for potential applications in chronic HBV-infected patients, recombinant HBV is minimally affected by vector-targeting immune reactions, in distinct contrast to other virus vectors. Needless to say, for studying basic virology of hepadnaviruses, only recombinant hepadnaviruses are irreplaceable tools for obtaining meaningful results. So far, however, studies that actually take advantage of the reported recombinant hepadnavirus vector systems to address unanswered virological questions and unmet clinical demands have been rare and mostly restricted to labs that originally developed the systems. The reasons behind such apparent lack of application are manifold.

Firstly, large-scale preparation of recombinant viruses is a very cumbersome process, especially for poorly replicative constructs. The use of stronger promoter, such as CMV promoter, instead of native $\mathrm{Cp}$ promoter to drive pgRNA transcription could enhance, to a limited degree, the production of progeny viruses. In future, identifying and counteracting cellular mechanisms restricting hepadnaviral replication might give rise to novel production systems. The necessity of providing trans-complementation of viral proteins for most designs further complicates production and may also incur the risk of wild-type contamination through homologous recombination [38], the mitigation of which would require extensive synonymous mutations. Engineering stably-transfected cell lines that continuously produce recombinant viruses at acceptable levels in the supernatants will significantly boost adoption and application of recombinant hepadnavirus vectors.

Secondly, infection systems for HBV used to be tedious and costly to establish and use, especially for in vivo applications. The identification of NTCP receptor for HBV and demonstration that NTCP-overexpressing hepatoma cell lines supporting wild-type and recombinant HBV infection no doubt represent a significant advance in this respect [29]. With the advent and general availability of easier-to-handle in vitro HBV infection systems, like HepG2/NTCP [29], interest in and applications of viable recombinant hepadnavirus vectors can be expected to grow. It is also possible that with further understanding of HBV infection mechanisms, which could be significantly promoted by the use of reporter-expressing recombinant $\mathrm{HBV}$, transgenic mice supporting $\mathrm{HBV}$ infection might be eventually obtained. In addition, advances in WHV reverse genetics might also enable the development of recombinant WHV vectors usable in this important model of HBV.

Thirdly, most reported recombinant hepadnavirus vectors have been demonstrated using only one or two cargo genes (Table 1) and only our lab's work has used non-protein cargos [37]. Such limited demonstration of recombinant hepadnaviruses' capability does not help in attracting potentially interested researchers. There are, of course, inherent restrictions on possible choices of cargo genes 
(see previous sections), but extensive and in-depth characterization of existing vectors for their ability to deliver commonly used, as well as novel cargo sequences with relevant functions, will surely encourage and facilitate wider applications of recombinant hepadnaviruses in both laboratory and clinical settings.

Last, but not least, integration of hepadnavirus sequences into hepatocyte genomes is often detected in chronically-infected subjects and has been linked, at least in some studies, to HCC development [1-3]. Unlike retroviruses and lentiviruses, integration of viral genome into a host chromosome is not a necessary step in hepadnavirus life cycle, and probably represents an opportunistic event during the long-term presence and activity of hepadnaviruses in hepatocytes. Unfortunately, fairly limited information is available on the integration mechanisms, as well as preferred integration sites or lack thereof. Similarly, a potential link to HCC has also been proposed for HBx protein without detailed understanding of the underlying molecular details $[1,20]$. These constitute a major safety concern for any potential in vivo applications of recombinant HBV for subjects not chronically infected with HBV. Further understanding of hepadnavirus integration and HBx functions, which could be aided by studies using recombinant hepadnaviruses in vivo and in vitro, might eventually enable more realistic evaluation of the associated risks and allow recombinant HBV-mediated gene delivery to be applicable to more patients.

Acknowledgments: This work was supported by the National Key Project for Infectious Diseases of China (2012ZX10002-006, 2012ZX10004-503, 2012ZX10002012-003), National Basic Research Program of China (2012CB519002), National High-Tech Program of China (2012AA02A407), Natural Science Foundation of China (31071143, 31170148), Shanghai Municipal R\&D Program (11DZ2291900, GWDTR201216), and MingDao Project of Fudan University.

Conflicts of Interest: The authors declare no conflict of interest.

\section{References}

1. Liang, T.J. Hepatitis B: The virus and disease. Hepatology 2009, 49, S13-S21. [CrossRef] [PubMed]

2. Seeger, C.; Mason, W.S. Hepatitis B virus biology. Microbiol. Mol. Biol. Rev. 2000, 64, 51-68. [CrossRef] [PubMed]

3. Seeger, C.; Mason, W.S. Molecular biology of hepatitis B virus infection. Virology 2015, 479, $672-686$. [CrossRef] [PubMed]

4. Littlejohn, M.; Locarnini, S.; Yuen, L. Origins and evolution of hepatitis B virus and hepatitis D virus. Cold Spring Harb. Perspect. Med. 2016, 6. [CrossRef] [PubMed]

5. MacLachlan, J.H.; Cowie, B.C. Hepatitis B virus epidemiology. Cold Spring Harb. Perspect. Med. 2015, 5. [CrossRef] [PubMed]

6. Drexler, J.F.; Geipel, A.; Konig, A.; Corman, V.M.; van Riel, D.; Leijten, L.M.; Bremer, C.M.; Rasche, A.; Cottontail, V.M.; Maganga, G.D.; et al. Bats carry pathogenic hepadnaviruses antigenically related to hepatitis B virus and capable of infecting human hepatocytes. Proc. Natl. Acad. Sci. USA 2013, 110, 16151-16156. [CrossRef] [PubMed]

7. Hahn, C.M.; Iwanowicz, L.R.; Cornman, R.S.; Conway, C.M.; Winton, J.R.; Blazer, V.S. Characterization of a novel hepadnavirus in the White Sucker (Catostomus commersonii) from the Great Lakes Region of the United States. J. Virol. 2015, 89, 11801-11811. [CrossRef] [PubMed]

8. Suh, A.; Brosius, J.; Schmitz, J.; Kriegs, J.O. The genome of a Mesozoic paleovirus reveals the evolution of hepatitis B viruses. Nat. Commun. 2013, 4. [CrossRef] [PubMed]

9. Liu, W.; Pan, S.; Yang, H.; Bai, W.; Shen, Z.; Liu, J.; Xie, Y. The first full-length endogenous hepadnaviruses: Identification and analysis. J. Virol. 2012, 86, 9510-9513. [CrossRef] [PubMed]

10. Gilbert, C.; Feschotte, C. Genomic fossils calibrate the long-term evolution of hepadnaviruses. PLoS Biol. 2010, 8. [CrossRef] [PubMed]

11. Gilbert, C.; Meik, J.M.; Dashevsky, D.; Card, D.C.; Castoe, T.A.; Schaack, S. Endogenous hepadnaviruses, bornaviruses and circoviruses in snakes. Proc. R. Soc. London B Bio. Sci. 2014, 281. [CrossRef] [PubMed]

12. Watashi, K.; Wakita, T. Hepatitis B virus and hepatitis D virus entry, species specificity, and tissue tropism. Cold Spring Harb. Perspect. Med. 2015, 5. [CrossRef] [PubMed] 
13. Winer, B.Y.; Ploss, A. Determinants of hepatitis B and delta virus host tropism. Curr. Opin. Virol. 2015, 13, 109-116. [CrossRef] [PubMed]

14. World Health Organization Hepatitis B. World Health Organization Fact Sheet 204 (Revised July 2013). Available online: http://www.who.int/mediacentre/factsheets/fs204/en/ (accessed on 10 December 2013).

15. Mason, W.S. Animal models and the molecular biology of hepadnavirus infection. Cold Spring Harb. Perspect. Med. 2015, 5. [CrossRef] [PubMed]

16. Hu, J.M.; Seeger, C. Hepadnavirus genome replication and persistence. Cold Spring Harb. Perspect. Med. 2015, 5. [CrossRef] [PubMed]

17. Protzer, U.; Nassal, M.; Chiang, P.W.; Kirschfink, M.; Schaller, H. Interferon gene transfer by a hepatitis B virus vector efficiently suppresses wild-type virus infection. Proc. Natl. Acad. Sci. USA 1999, 96, 10818-10823. [CrossRef] [PubMed]

18. Ho, T.C.; Jeng, K.S.; Hu, C.P.; Chang, C. Effects of genomic length on translocation of hepatitis B virus polymerase-linked oligomer. J. Virol. 2000, 74, 9010-9018. [CrossRef] [PubMed]

19. Bartenschlager, R.; Schaller, H. Hepadnaviral assembly is initiated by polymerase binding to the encapsidation signal in the viral RNA genome. EMBO J. 1992, 11, 3413-3420. [PubMed]

20. Feitelson, M.A.; Bonamassa, B.; Arzumanyan, A. The roles of hepatitis B virus-encoded X protein in virus replication and the pathogenesis of chronic liver disease. Expert Opin. Ther. Targets 2014, 18, 293-306. [CrossRef] [PubMed]

21. Belloni, L.; Pollicino, T.; de Nicola, F.; Guerrieri, F.; Raffa, G.; Fanciulli, M.; Raimondo, G.; Levrero, M. Nuclear HBx binds the HBV minichromosome and modifies the epigenetic regulation of cccDNA function. Proc. Natl. Acad. Sci. USA 2009, 106, 19975-19979. [CrossRef] [PubMed]

22. Lucifora, J.; Arzberger, S.; Durantel, D.; Belloni, L.; Strubin, M.; Levrero, M.; Zoulim, F.; Hantz, O.; Protzer, U. Hepatitis B virus $X$ protein is essential to initiate and maintain virus replication after infection. J. Hepatol. 2011, 55, 996-1003. [CrossRef] [PubMed]

23. Tsuge, M.; Hiraga, N.; Akiyama, R.; Tanaka, S.; Matsushita, M.; Mitsui, F.; Abe, H.; Kitamura, S.; Hatakeyama, T.; Kimura, T.; et al. HBx protein is indispensable for development of viraemia in human hepatocyte chimeric mice. J. Gen. Virol. 2010, 91, 1854-1864. [CrossRef] [PubMed]

24. Thung, S.N.; Gerber, M.A.; Purcell, R.H.; London, W.T.; Mihalik, K.B.; Popper, H. Animal model of human disease. Chimpanzee carriers of hepatitis B virus. Chimpanzee hepatitis B carriers. Am. J. Pathol. 1981, 105, 328-332. [PubMed]

25. Dandri, M.; Burda, M.R.; Zuckerman, D.M.; Wursthorn, K.; Matschl, U.; Pollok, J.M.; Rogiers, X.; Gocht, A.; Kock, J.; Blum, H.E.; et al. Chronic infection with hepatitis B viruses and antiviral drug evaluation in uPA mice after liver repopulation with tupaia hepatocytes. J. Hepatol. 2005, 42, 54-60. [CrossRef] [PubMed]

26. Dandri, M.; Burda, M.R.; Torok, E.; Pollok, J.M.; Iwanska, A.; Sommer, G.; Rogiers, X.; Rogler, C.E.; Gupta, S.; Will, H.; et al. Repopulation of mouse liver with human hepatocytes and in vivo infection with hepatitis B virus. Hepatology 2001, 33, 981-988. [CrossRef] [PubMed]

27. Kock, J.; Nassal, M.; MacNelly, S.; Baumert, T.F.; Blum, H.E.; von Weizsacker, F. Efficient infection of primary tupaia hepatocytes with purified human and woolly monkey hepatitis B virus. J. Virol. 2001, 75, 5084-5089. [CrossRef] [PubMed]

28. Gripon, P.; Rumin, S.; Urban, S.; le Seyec, J.; Glaise, D.; Cannie, I.; Guyomard, C.; Lucas, J.; Trepo, C.; Guguen-Guillouzo, C. Infection of a human hepatoma cell line by hepatitis B virus. Proc. Natl. Acad. Sci. USA 2002, 99, 15655-15660. [CrossRef] [PubMed]

29. Yan, H.; Zhong, G.; Xu, G.; He, W.; Jing, Z.; Gao, Z.; Huang, Y.; Qi, Y.; Peng, B.; Wang, H.; et al. Sodium taurocholate cotransporting polypeptide is a functional receptor for human hepatitis B and D virus. eLife 2012, 1. [CrossRef] [PubMed]

30. Chang, L.J.; Hirsch, R.C.; Ganem, D.; Varmus, H.E. Effects of insertional and point mutations on the functions of the duck hepatitis B virus polymerase. J. Virol. 1990, 64, 5553-5558. [PubMed]

31. Chaisomchit, S.; Tyrrell, D.L.; Chang, L.J. Development of replicative and nonreplicative hepatitis B virus vectors. Gene Ther. 1997, 4, 1330-1340. [CrossRef] [PubMed]

32. Wang, L.; Kaneko, S.; Honda, M.; Kobayashi, K. Approach to establishing a liver targeting gene therapeutic vector using naturally occurring defective hepatitis B viruses devoid of immunogenic T cell epitope. Virus Res. 2002, 85, 187-197. [CrossRef] 
33. Yoo, J.; Rho, J.; Lee, D.; Shin, S.; Jung, G. Hepatitis B virus vector carries a foreign gene into liver cells in vitro. Virus Genes 2002, 24, 215-224. [CrossRef] [PubMed]

34. Deng, Q.; Mancini-Bourgine, M.; Zhang, X.; Cumont, M.C.; Zhu, R.; Lone, Y.C.; Michel, M.L. Hepatitis B virus as a gene delivery vector activating foreign antigenic $\mathrm{T}$ cell response that abrogates viral expression in mouse models. Hepatology 2009, 50, 1380-1391. [CrossRef] [PubMed]

35. Wang, Z.; Zhu, K.; Bai, W.; Jia, B.; Hu, H.; Zhou, D.; Zhang, X.; Zhang, X.; Xie, Y.; Bourgine, M.M.; et al. Adenoviral delivery of recombinant hepatitis $\mathrm{B}$ virus expressing foreign antigenic epitopes for immunotherapy of persistent viral infection. J. Virol. 2014, 88, 3004-3015. [CrossRef] [PubMed]

36. Wang, Z.; Wu, L.; Cheng, X.; Liu, S.; Li, B.; Li, H.; Kang, F.; Wang, J.; Xia, H.; Ping, C.; et al. Replication-competent infectious hepatitis B virus vectors carrying substantially sized transgenes by redesigned viral polymerase translation. PLOS ONE 2013, 8, e60306. [CrossRef] [PubMed]

37. Hong, R.; Bai, W.; Zhai, J.; Liu, W.; Li, X.; Zhang, J.; Cui, X.; Zhao, X.; Ye, X.; Deng, Q.; et al. Novel recombinant hepatitis B virus vectors efficiently deliver protein and RNA encoding genes into primary hepatocytes. J. Virol. 2013, 87, 6615-6624. [CrossRef] [PubMed]

38. Untergasser, A.; Protzer, U. Hepatitis B virus-based vectors allow the elimination of viral gene expression and the insertion of foreign promoters. Hum. Gene Ther. 2004, 15, 203-210. [CrossRef] [PubMed]

39. Liu, J.; Cheng, X.; Guo, Z.; Wang, Z.; Li, D.; Kang, F.; Li, H.; Li, B.; Cao, Z.; Nassal, M.; et al. Truncated active human matrix metalloproteinase- 8 delivered by a chimeric adenovirus-hepatitis $B$ virus vector ameliorates rat liver cirrhosis. PLoS ONE 2013, 8, e53392. [CrossRef] [PubMed]

40. Nishitsuji, H.; Ujino, S.; Shimizu, Y.; Harada, K.; Zhang, J.; Sugiyama, M.; Mizokami, M.; Shimotohno, K. Novel reporter system to monitor early stages of the hepatitis B virus life cycle. Cancer Sci. 2015, 106, 1616-1624. [CrossRef] [PubMed]

41. Chen, A.; Kao, Y.F.; Brown, C.M. Translation of the first upstream ORF in the hepatitis B virus pregenomic RNA modulates translation at the core and polymerase initiation codons. Nucleic Acids Res. 2005, 33, 1169-1181. [CrossRef] [PubMed] 